\title{
The effect of "Internet of Things" on supply chain integration and performance: An organisational capability perspective
}

\author{
Tharaka de Vass \\ College of Business \\ Victoria University \\ Melbourne, Australia \\ Tharaka.DeVass@vu.edu.au
}

Himanshu Shee

College of Business

Victoria University

Melbourne, Australia

\section{Shah Miah}

College of Business

Victoria University

Melbourne, Australia

\section{Abstract}

The Internet of things (IoT) is a next generation of Internet connected embedded ICT systems in a digital environment to seamlessly integrate supply chain and logistics processes. Integrating emerging IoT into the current ICT systems can be unique because of its intelligence, autonomous and pervasive applications. However, research on the IoT adoption in supply chain domain is scarce and acceptance of the IoT into the retail services in specific has been overly rhetoric. This study is drawn upon the organisational capability theory for developing an empirical model considering the effect of IoT capabilities on multiple dimensions of supply chain process integration, and in turn improves supply chain performance as well as organisational performance. Cross-sectional survey data from 227 Australian retail firms was analysed using structural equation modelling (SEM). The results indicate that IoT capability has a positive and significant effect on internal, customer-, and supplier-related process integration that in turn positively affects supply chain performance and organisational performance. Theoretically, the study contributes to a body of knowledge that integrates information systems research into supply chain integration by establishing an empirical evidence of how IoT-enabled process integration can enhance the performance at both supply chain and organisational level. Practically, the results inform the managers of the likely investment on IoT that can lead to chain's performance outcome.

Keywords: Internet of Things, supply chain integration, supply chain performance, firm performance, organisational capability theory

\section{Introduction}

Internet of Things (IoT) represents an advancement in technological innovation connecting objects and devices through Internet (Atzori, Iera, \& Morabito, 2010). The network of objects (e.g. devices, vehicles, machines, containers), embedded with sensors and software has the potential to collect and communicate data over Internet (Edwards \& Hopkins, 2018). IoT 
platform thus facilitates "things" to be identified, located, sensed and controlled via the global platform (Borgia, 2014). It is viewed as progression of information and communication technology (ICT) (e.g. computers, ERP, bar code, email, fax, phone, and WMS) applications that are helpful to capture and share data in a network of organisations on real-time basis (Borgia, 2014). This "digitally upgrading" of conventional objects via Internet connectivity generates added capabilities to its functionality (Mattern \& Floerkemeier, 2010). IoT capabilities may differ to previous ICT capabilities due to their ubiquity, intelligence and autonomy (Constantinides, Kahlert, \& de Vries, 2017).

Aside, conventional ICT technologies help monitor supply chain functions such as purchasing, transportation, storage, distribution, sales and returns (Vanpoucke, Vereecke, \& Muylle, 2017). With many other smart devices recently joining the list under the newly coined IoT umbrella of technologies, the potential to address the information capture and exchange in real-time has multiplied (Atzori et al., 2010; Borgia, 2014). Although the advances in IoT applications in the form of sensor is expected to revolutionise retail sector (Kahlert, Constantinides, \& de Vries, 2017), its acceptance and potential to integrate supply chain processes is largely under developed both for theoretical and practical implications.

Although there have been a number of studies that have investigated the ICT-enabled supply chain processes integration in improving the performance ( $\mathrm{Li}$, Yang, Sun, \& Sohal, 2009; Qrunfleh \& Tarafdar, 2014; Rai, Patnayakuni, \& Seth, 2006; Vanpoucke et al., 2017), no study is documented to empirically assess the effect of emerging IoT adoption on supply chain integration. Supply chain integration includes both inter- and intra-organisational integration across the entire supply chain through a collaborative mechanism (Alfalla-Luque, MedinaLopez, \& Dey, 2013), that can generate greater customer value by offering superior services (Christopher \& Towill, 2001). In a scenario of network-based competition, the strength of a supply chain is determined by how effective the flow of goods and services is, information exchange, and funds flows (Rai et al., 2006). IoT is perceived to strengthen the supply chain integration by connecting the objects through Internet (Ping, Liu, Zhou, \& Wang, 2011; Tu, 2018). Adoption and use of IoT help organisation building its capability. From organisational capability theory perspective, IoT is likely to enhance the capability to integrate the suppliers, customers and intra-organisational logistics processes.

IoT bridges the gap between physical and digital world by synchronising the information flow with the physical flow for greater supply chain integration (Ping et al., 2011). IoT capability is defined as additional capabilities gained by supply chains with everyday objects being embedded with technology that provides identifying, sensing, networking and processing capabilities to communicate with other devices and services over the Internet (Whitmore, Agarwal, \& Da Xu, 2014).

Given that retail supply chains are primarily demand driven, intense digital connectivity and coordination within the supply chain via adoption of new technology can be considered as an intervention in service improvement (Fleisch \& Tellkamp, 2005). The emerging IoT paradigm, therefore, may play a significant role in the retail industry to manage supply networks in response to customer demands (Yu, Subramanian, Ning, \& Edwards, 2015). Moreover, the supply chain literature on IoT application is broadly rhetoric, technology and architecture focused and quite nascent (Mishra et al., 2016). Due to enthusiasm on technological adoption in data transparency and visibility to achieve supply chain process integration, the research 
on IoT within this context is timely (Ben-Daya, Hassini, \& Bahroun, 2017; Dubey, Gunasekaran, Childe, Papadopoulos, \& Wamba, 2017; Mishra et al., 2016; Tu, 2018).

The question is what extent the emerging list of technologies classified as 'IoT' can facilitate external (i.e. suppliers and customers) and internal (cross-functional operations) process integration to deliver better supply chain performance and firm performance. This study, therefore, aims to empirically investigate the perceived effect of IoT adoption on supply chain process integration that in turn enhances both supply chain, and firm performance.

This paper is organised as follows. First, the literature on organisational capability theory, supply chain integration, and IoT is reviewed to propose a conceptual framework for IoTenabled supply chain process integration and performance. The methodology of data collection and analysis technique using SEM modelling is then outlined. The discussion of results, theoretical and managerial implications of the findings are then discussed. Finally, we summarise the work and outline some limitations within the study context.

\section{Background literature review}

\subsection{Organisational capability theory}

IoT adoption can be viewed as an additional capability that may add value to the current configuration of ICT capability within any organisation. It is important for studies to utilise and treat IoT capability as a progression of ICT capability that may facilitate intra- and interorganisational communication and information flows in more integrated way (Borgia, 2014). The intra- and inter-organisational information sharing (Huh, Yook, \& Kim, 2008), information communication (Huh et al., 2008; Kusunoki, Nonaka, \& Nagata, 1998), and inter-firm relationships (Lorenzoni \& Lipparini, 1999) together represent process integration capabilities. We, therefore, intend to develop an insight from the literature that organisations can build additional capabilities by adopting IoT into the mainstream business running on the legacy of ICT backbone. The inter- and intra-organisational communication and information exchange are perceived to be facilitated by IoT capability.

Organisational capability theory therefore can be argued to underpin this research. Organisational capability perspective, related to resource-based view theory, suggests that a firm must develop its own resources and capabilities for performance improvement (Huo, 2012; Rai et al., 2006). Integration per se is a higher order process capability that can directly influence firm performance (Huo, 2012; Verona, 1999). Further, organisational capability theory suggests that internal integration can directly affect external integration where internal process integration is the base for the development of the firm's external process integration (Huo, 2012; Zhao, Huo, Selen, \& Yeung, 2011). Verona (1999) suggest that internal capabilities include internal communication, process integration and job training, while external capabilities represent external communication and networks of partners. Bharadwaj (2000) further argues that ICT implementation itself cannot have a direct effect on performance; rather it needs to be blended with the other organisational resources (e.g. human and financial resources) for performance improvement. Hence, IoT can be thought of improving the integration capability of an organisation perceived the way ICT does.

\subsection{Supply chain integration}

In the current dynamic and competitive business environment, where it is the supply chains that compete rather than individual organisations (Christopher, 2016; Christopher \& Towill, 
2001), the increased supply chain performance enhances sustainable competitive advantage (Seuring \& Müller, 2008; Spekman, Kamauff Jr, \& Myhr, 1998). In conceptualising supply chain management (Christopher, Crum, \& Holweg, 2011; Ellram \& Cooper, 1993; Ho, Au, \& Newton, 2002), the supply chain integration represents a mechanism for improving supply chain performance (Alfalla-Luque et al., 2013; Ataseven \& Nair, 2017).

Supply chain integration can be defined as collaborative inter- and intra-organisational management on the strategic, tactical and operational business processes to achieve effective and efficient flows of products, information and funds to provide the maximum value to the end customer at the lowest cost and the greatest speed (Alfalla-Luque et al., 2013; Huo, 2012; $\mathrm{Yu}, 2015$; Zhao et al., 2011). Being a leading research theme that combines information systems knowledge into supply chain management literature, integration has been viewed as the digital connection of business processes within the organisation, and between organisations involving upstream suppliers and downstream customers (Ataseven \& Nair, 2017). In addition, many scholars consider supply chain integration having three dimensions: internal process integration, upstream supplier integration and downstream customer integration (Alfalla-Luque et al., 2013; Ataseven \& Nair, 2017; Näslund \& Hulthen, 2012).

Internal integration refers to the breakdown of cross-functional barriers within an organisation via synchronised processes by facilitating real-time information sharing across business functions, strategic collaboration and coordination to achieve superior performance ( $\mathrm{Yu}, 2015$; Zhao et al., 2011). Supplier and customer integration refers to strategic information sharing, mutual planning and collaboration between the focal organisation and its upstream suppliers and downstream customers in managing synchronised processes (Huo, 2012; Yu, 2015). Supplier integration involves collaboration between a focal organisation and its suppliers in managing cross-firm business processes; customer integration enables a deeper understanding of market expectations and opportunities for a more accurate and rapid response to customer requirements (Ataseven \& Nair, 2017; Huo, 2012). Conceptually, the goal of integration is to achieve cost efficiency and delivery effectiveness across the entire supply chain, while creating value for the customer (Näslund \& Hulthen, 2012). Frohlich and Westbrook (2001) suggest the 'arcs of integration' theory where organisations with greater supply chain integration will benefit from superior performance outcomes. Abundance of studies in literature have shown the positive effect of supply chain integration on its performance (Ataseven \& Nair, 2017; Flynn, Huo, \& Zhao, 2010; Huo, 2012).

\subsection{Internet of Things (IOT) in process integration}

The advancement of Internet-enabled network of infrastructure from RFID readers to $4 \mathrm{G}$ highspeed wireless communication acts as catalyst behind the growth of these disruptive technologies designed with low-power, low-transmission, machine-to-machine level communication to send and receive data (Souders, 2015). The data however is not disruptive by itself. Ample of logistics related data was then gathered using even existing devices, but they were soiled between functional areas and was seldom available on a real-time basis. Instead, capturing and analysing more relevant data become essential tasks upon which disruptive technologies are built (Wasserman \& Mahmoodi, 2017). IoT therefore promises substantially for this purpose.

Atzori et al. (2010) explain how the IoT is converged with three key visions: things-oriented, Internet-oriented and semantic-oriented. Thus, IoT architecture encompasses the objects that captures data, communicates with the real world and actuates; the Internet global platform 
including cloud that facilitates transmission; and hosting and processing of data as well as its information synthesis and processing ability. Even though current IoT applications are reported to be in its infancy compared to its broader potential, its intelligence, autonomous and pervasive applications have made it popular through cost-effective miniaturisation (Uckelmann, Harrison, \& Michahelles, 2011). As IoT technologies became more effective and affordable in recent years, its adoption and deployment in supply chain operations progressively grows despite challenges (Verdouw, Wolfert, Beulens, \& Rialland, 2016).

ICT, as digital enabler for supply chain integration, promotes effective information flow (Rai et al., 2006; Yu, 2015). The additional capabilities generated by IoT technologies are argued to potentially facilitate the information capture and sharing among the partners (Ben-Daya et al., 2017; Tu, 2018). Thus, IoT, has the capability to sense supply chain processes, improving visibility, accuracy, traceability, interoperability and collaborative decisions along the chains (Reaidy, Gunasekaran, \& Spalanzani, 2015). Authors acknowledge supply chains in general (Borgia, 2014) and retail supply chains in particular (Lee \& Lee, 2015; Yu et al., 2015) as a key industry application domain of IoT. Ben-Daya et al. (2017) argues that IoT is one of the key founding technologies of Industry 4.0. Zhou, Liu, and Zhou (2015) argue for integration of IoT into logistic information helping the partners to capture data and use them effectively in decision making.

Current supply chain applications of IoT are reported to take various forms such as RFID which requires a more unified, standardised and investment-oriented approach to exploit widespread smart devices, GPS and smartphones that come with various built in IoT functionalities (Borgia, 2014; Ng, Scharf, Pogrebna, \& Maull, 2015; Perera, Member, Jayawardena, \& Chen, 2015; Yu et al., 2015). Therefore, IoT should not be viewed as a technology limited to large, resourceful operations, but as a generally available capability. However, IoT deployment is reported currently as fragmented and lacks interoperability to realise its full potential due to issues with standardisation, architecture, security and privacy (Borgia, 2014). Therefore, further investigation on the perceived impact of IoT on supply chain integration process is needed.

Literature on IoT is emerging and quite rhetoric on its adoption (Mishra et al., 2016). By analysing over 300 IoT publications, $\mathrm{Xu}, \mathrm{He}$, and Li (2014) find mounting scholarly interest on IoT. The focus so far is mainly on conceptual definitions, model building, key technology and features (Liu \& Gao, 2014). Whitmore et al. (2014) reviewed 127 IoT focussed publications mostly confined to a technology perspective and not well represented in the management and operations literature. Review of 1,556 articles published on IoT from 2000 to 2015, Mishra et al. (2016) find the field dominated by conceptualisations and few case studies on applications of IoT. The authors reveal that greater part of the literature focuses on technology perspective and hardly any study looks at the relationship between IoT adoption for improved supply chain and organisational performance. Moreover, supply chain integration being an underlying concept (Reaidy et al., 2015; Tu, 2018), the vital link between IoT adoption and supply chain performance is largely unexplored within the literature.

Ping et al. (2011)'s concept paper on agile supply chain management is one of the few which seeks to explain how IoT can synchronise and strengthen the goods and information flow to improve supply chain integration. Similarly, Reaidy et al. (2015) propose an IoT infrastructure for collaborative warehousing, recognising that the new environment requires supply chain with greater integration. Further, Yan et al. (2014), through a single case study under 
laboratory conditions explore the relationship between IoT and supply chain integration. These authors suggest that IoT is an effective approach for supply chain integration to achieve overall supply chain performance. Nonetheless, the authors offer no empirical evidence of IoT that can improve supply chain process integration from the perspective of organisational capability theory.

Overall, the academic literature does not provide enough evidence on the relationship between IoT capability and supply chain process integration from the supply chain perspective or specifically, the retail supply chain context. Despite the emergence of laboratory-based studies, quantitative studies on the capabilities of IoT are not yet available (Verdouw et al., 2016). Therefore, this study addresses the knowledge gap by examining empirically whether IoT can strengthen supply chain integration capability to influence performance in the Australian retail industry. Mishra et al. (2016) posit that socioorganisational implications of IoT adoption will benefit both academics and practitioners than focusing only on technology per se.

\subsection{Conceptual research framework and hypotheses development}

The conceptual framework in this study is built upon the process integration model proposed by Huo (2012), who empirically investigates operational and financial performance significantly influenced by integration mechanism from a manufacturing industry perspective. In his model, Huo (2012) includes three sub-dimensions of integration: supplier, customer and intra-organisational integration. Literature evidences a wide range of studies on integration primarily focused on the relationship between supply chain integration and performance (Fabbe-Costes \& Jahre, 2008; Huo, 2012; Kim, 2009). Rai et al. (2006), while acknowledging the positive effect of digitally enabled supply chain integration on firm performance, draw upon ICT capability as a separate construct. Further, Yu (2015), building on Huo (2012)'s model, considers ICT as a separate construct having a significant effect on the three dimensions of supply chain integration. However, none of the existing studies so far used IoT as an enabler of suppliers, customers and internal integration in the context we have drawn in this study. This study draws on ICT-enabled organisational capabilities perspective, that is the theoretical notion of how ICT shapes higher-order process capabilities for performance gains (Rai et al., 2006). This concept is extended to investigate the hierarchy of IoT-related capabilities and their effect on organisational performance. While the studies on emerging IoT technology remain rhetoric in the literature, this study fills the gap by examining the perceived effect of IoT capability on the three dimensions of supply chain integration, and subsequent effect on supply chain and organisational performance. This addresses the gap in the targeted literature that we have discussed above.

\subsubsection{Hypotheses development}

IoT is an emerging global Internet-based information service architecture facilitating the exchange of goods in global supply chain networks by generating value for all partners (Lee \& Lee, 2015; Liu \& Sun, 2011; Weber, 2009). The pervasive presence of RFID tags, sensors, actuators, smart devices and machines and mobile phones are reported to have the capability of conducting real-time monitoring of almost every link from purchasing, transportation, storage, distribution, sales and returns in contemporary supply chains (Atzori et al., 2010; Haddud, DeSouza, Khare, \& Lee, 2017). This facilitates a safe and trustworthy platform to exchange information related to goods and services in a global supply chain (Mishra et al., 2016). Hence, IoT has the potential beyond traditional ICT to address the information gap in 
existing supply chains by capturing additional data flowing among supply chain entities, processes, equipment and people, and transfer, process and action in real-time (Ben-Daya et al., 2017; Borgia, 2014). The extent literature claims that IoT has the capability to assist with real-time data capture thereby facilitating inter- and intra-firm communication and integration (Ping et al., 2011; Yan et al., 2014). Zara, for instance, achieves planning flexibility, effective replenishment, shorter lead times and product variations with the assistance of such handheld devices (Qrunfleh \& Tarafdar, 2014). IoT further helps in fleet tracking; shipment condition monitoring; storage conditions of cold chain/perishable products and; product tracking, thereby integrating suppliers into buyers' communication process. Further, product delivery process, shop guidance, customer shopping behaviour, and product tracking where IoT can help customers by integrating them in to the process. Therefore, the hypothesis can be formulated as,

Hypothesis H1: IoT capability has a positive effect on supplier integration.

H2: IoT capability has a positive effect on internal integration.

H3: IoT capability has a positive effect on customer integration.

The literature posits that internal integration improves external integration in terms of supplier and customer integration (Huo, 2012). Organisational capability theory suggests that internal integrative capabilities can directly affect external integration capabilities (Huo, 2012; Zhao et al., 2011). Information exchange with suppliers using IoT technology can improve the understanding of joint planning, forecasting and partnerships. Information exchange via IoT can help organisations to understand the customer requirements and to collaborate with customers for better demand planning and customer service. The use of internal IoT can be a base to develop IoT capability to the entire supply chain. Therefore, it is hypothesised that,

Hypothesis H4: IoT-enabled internal integration has a positive effect on supplier integration.

H5: IoT-enabled internal integration has a positive effect on customer integration.

Literature suggests that partner integration can minimise cost via waste reduction and asset utilisation (Näslund \& Hulthen, 2012) and also help supply chains to be more flexible, adaptive, reactive and responsive to cope with risks and market uncertainty (Reaidy et al., 2015). Therefore, all three dimensions of supply chain integration improves supply chain performance (Huo, 2012; Vanpoucke et al., 2017). Digitally enabled supply chain integration has a positive effect on performance (Rai et al., 2006; Yu, 2015). IoT can improve the way people and systems collaborate and coordinate supply chain processes, analyse captured data. This helps to identify optimisation prospects and effective procedures for performance gains throughout the entire supply chain via operational efficiency, quality, flexibility, delivery reliability and customer experience. The three dimensions of supply chain integration via IoT, therefore, are likely to influence supply chain performance. Hence, the hypotheses can be formulated as,

Hypothesis H6: IoT-enabled supplier integration has positive influence on supply chain performance.

H7: IoT-enabled internal integration has positive influence on supply chain performance.

H8: IoT-enabled customer integration has positive influence on supply chain performance. 
The literature further suggests that ICT-enabled supply chain performance impacts organisational performance positively (Qrunfleh \& Tarafdar, 2014; Vanpoucke et al., 2017). The real time information provided by IoT helps track supply chain activities, from product design to the end users, providing accurate and timely information to help organisations respond to the market changes (Mishra et al., 2016). While supply chain strategy yields performance by focussing on cost, quality, delivery and flexibility improvement (Gunasekaran, Patel, \& McGaughey, 2004), it attempts to align with the firm objectives of improving triple bottom line performance to generate environmental, social, and economic benefits (Carter \& Rogers, 2008; Elkington, 1997). Likewise, IoT-enabled supply chain performance influences firms' economic performance while caring for environment and social dimensions. Hence, the following hypothesis is proposed.

Hypothesis H9: IoT-enabled supply chain performance is positively related to organisations' sustainable performance.

\subsubsection{Control variables}

Organisational size, characterised by employee number, is often found to determine firms actions and performance (Rai et al., 2006). Large organisations offer strength to acquire capabilities due to its resource availability, the economics of scale and the capacity to influence supply chain partners (Yu, 2015). This study includes organisations from multiple retail forms. The IoT application could vary on each retail form. The e-tail model relies more on information sharing as compared to physical goods flows in traditional bricks and mortar model. Therefore, organisational size and retail form were tested as control variables as they might have positive effect on retail performance.

\section{Methodology}

\subsection{Sample characteristics}

The respondent firms represented 49.8 percent from large size (employees $>200$ ), 49.8 percent from medium size (between 20 to 200 employees) and only 4.4 percent were small size (employees<20) (ABS Retail industry analysis, 2014). About 55.8 percent of the sample reported that their supply chains extended worldwide, while regional and local supply chains represented 30 and 14 percent respectively. About 56.8 percent of the organisations were traditional bricks and mortar store-based walk-in retailers, 38.8 percent were multimodal (or omnichannel) and only 4.4 percent were e-tailing. Table 1 shows sample distribution of retail sector (ABS Retail industry analysis, 2014). Overwhelming 96 percent of the respondents had over 2 years of managerial experience within their respective organisations. The respondents had titles such as CEO/Chairmen/MD/Director/General manager (15 percent), Operations/Supply Chain/Logistics manager (24.2 percent), Middle management (28.6 percent), IT manager (26.4 percent) and Others (5.8 percent). About 62 percent believed that they were engaged in high-level strategic decision making in supply chain operations with 14 percent perceiving them as the key decision maker and 48 percent involved in a considerable extent. 36 percent stated that their involvement is at a moderate extent. The majority (90 percent) perceived 'improve overall business performance' as a key motive for IoT adoption in their firm's supply chain operations, while 45 percent opted for cost reduction via operational efficiency and 35 percent for improve supply chain performance. 


\begin{tabular}{|l|c|c|}
\hline Retail sector (n=227) & Frequency & Percent \\
\hline Restaurant, café, takeaway & 26 & 11.5 \\
\hline Supermarkets, grocery & 37 & 16.3 \\
\hline Household goods (e.g. hardware, furniture) & 22 & 9.7 \\
\hline Clothing, footwear and personal accessories & 33 & 14.5 \\
\hline Electrical, electronic, computer & 22 & 9.7 \\
\hline Pharmaceutical, cosmetic, toiletry & 20 & 8.8 \\
\hline Motor vehicles \& parts & 11 & 4.8 \\
\hline Fuel and convenience stores & 9 & 4.0 \\
\hline Department stores & 25 & 11.0 \\
\hline Other & 22 & 9.7 \\
\hline
\end{tabular}

Table 1: Retail sectors represented in the sample

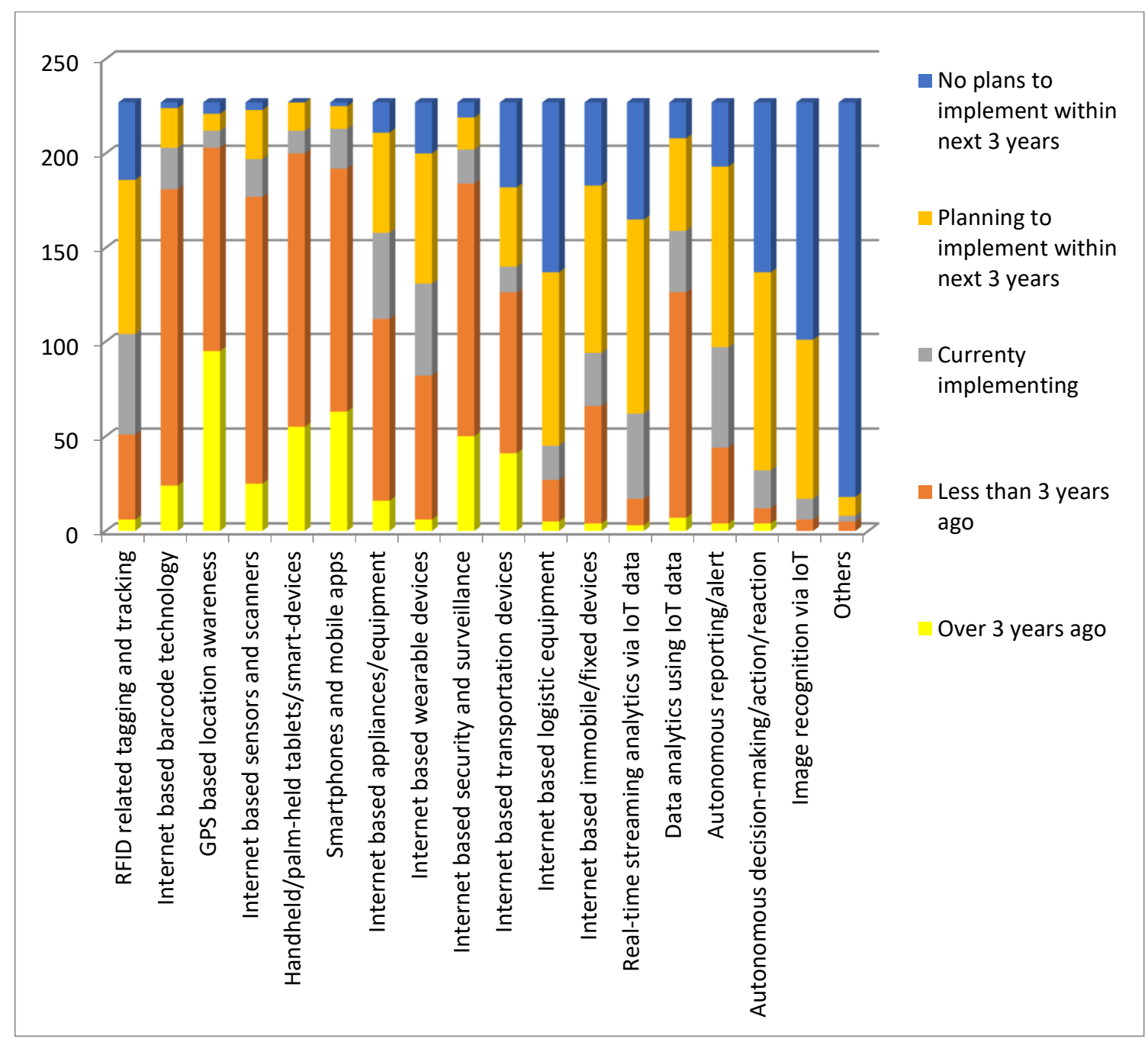

Figure 1: Current/planned adoption of IoT in respondents' supply chain operation

The Figure 1 displays how the respondents have implemented or planned to implement each form of IoT in their supply chain operations in late 2016. Even though RFID is widely reported 
as the primary form of IoT, the use of RFID related tagging and tracking is relatively low in retail supply chains. On the other hand, Internet-based barcode technology, GPS-based location awareness, Internet-based sensors and scanners, handheld/palm-held tablets/smart devices, smartphones and mobile apps and Internet-based security and surveillance demonstrate a high concentration of deployment. The findings confirm that, although IoT originates from the concept of RFID, it is now a central element on its own, with far-reaching capabilities and eclectic diffusion.

Every respondent firm had at least one form of IoT currently deployed within their supply chain operations. While 89 percent of respondents had four or more forms, 33 percent respondents had ten or more IoT forms deployed in their respective supply chain operations. These statistics confirm the diffusion of IoT in many primary forms in the retail supply chains in Australia.

\subsection{Sample and data collection}

The study used self-reported survey instrument for data collection from Australian retailers across industries. Retail firms from across industries in six states of Australia were randomly chosen from the Yellow Pages of Australian businesses directory and alphabetically listed to avoid duplication of cases (YellowPages, 2016; Yu, 2015; Zhao et al., 2011). A single key informant from each retailer was identified by inviting them through LinkedIn professional networking and Facebook. Prior research has successfully applied the similar online method to collect research data using questionnaire survey (Baltar \& Brunet Icart, 2011, 2012). The professional and academic connections were found to be successful as reported in prior similar studies (Yu, 2015; Yu, Jacobs, Salisbury, \& Enns, 2013; Zhao et al., 2011). The use of social networking sites of informants was effective to identify this "hard-to-reach"/"hard-to-involve" population (Baltar \& Brunet Icart, 2011, 2012). Then it was snowballed from initial connections to the second tier, third tier connections to identify possible informants belonged to the generated representative sample. When pre-contacted, potential informants from 546 retail firms agreed to participate in the survey. These potential respondents mainly represent either the supply chain and logistics area or IT department within that retailing business enabling them to respond to the questionnaire on IoT.

The link to the online Qualtrics survey was sent to the mailing list in a personally addressed email (Dillman, 2011). The questionnaire accompanied a cover letter explaining the objective and the potential contributions of the research. Following online reminders and follow-up phone calls, a total of 231 responses were collected. Four responses were discarded for their unengaged responses, reducing the sample to 227 usable cases that represented a 41 percent response rate.

\subsection{Measurement items and survey design}

The reliable and valid items were mostly adapted from previous literature through an extensive review. The minor changes were made to the questionnaire items to ensure they are aligned with the research questions, objectives and the method. Since IoT capability has not been measured in prior academic research, twelve items were newly developed based on their functionality published in academic literature (Atzori et al., 2010; Borgia, 2014; Perera et al., 2015) and consultancy manuscripts (DHL, 2015). The items were adapted keeping in view the core capabilities of IoT such as identify, monitor, measure, control, automate, analyse, information sharing and collaboration (DHL, 2015; Lee \& Lee, 2015). The integration measures 
were primarily adapted from Huo (2012) and Rai et al. (2006). They comprise of ten supplier integration items, ten internal integration items and nine customer integration items. All nine supply chain performance measurement items were adapted from a study by Schoenherr and Swink (2012). For firm performance, out of 11 items, six items were adapted from Rai et al. (2006), one from Yu et al. (2013) and additional social and environmental measurement items were adapted from Paulraj (2011), Dolbier, Webster, McCalister, Mallon, and Steinhardt (2005) and Zhu, Sarkis, and Lai (2012). Following prior similar studies (Huo, 2012; Yu, 2015), a sevenpoint Likert scale was chosen to measure all items with the responses ranging from 1 (strongly disagree) to 7 (strongly agree). The measurement items used in this study can be found in Table 2. In accordance with previous supply chain and operations management studies, the respondents were instructed to evaluate improvement relative to the performance of their main competitors over the last 3 years (Yu et al., 2013). It was clearly explained that the supply chain from the retail firm perspective not just includes their suppliers and customers but also the logistics intermediaries such as 3PL operators managing their transport and storage functions.

The survey followed Dillman (2011)'s design method guide on Internet surveys. A pre-pilot panel of five academics and five industry practitioners were asked to critique the questionnaire for content validity, appropriateness and clarity of questionnaire (Dillman, 2011). They identified some duplication and ambiguity in questionnaire items. After incorporating their feedback, the final version was entered in Qualtrics software and a link was created.

\section{Data analysis}

\subsection{Non-response bias and common method bias}

Non-response bias was assessed by comparing demographic variables of early and late respondents (at $60 \%$ to $40 \%$ split) via an independent sample t-test (Armstrong \& Overton, 1977). The t-test results indicated no significant differences between early and late responses at $p<0.05$ indicating no non-response issues (Armstrong \& Overton, 1977; Huo, 2012).

Harman's single-factor test was performed applying both exploratory factor analysis (EFA) and confirmatory factor analysis (CFA) (Podsakoff, MacKenzie, Lee, \& Podsakoff, 2003). First, the all-item EFA revealed seven distinct factors with eigenvalue above 1.0, explaining 65.92 percent of the total variance. The first factor explained 40.48 percent of the total variance, which is not the majority of the total variance. Second, the CFA was applied to Harman's single-factor model (Flynn et al., 2010; Podsakoff et al., 2003). The CFA demonstrated a poor model fit at $\chi^{2} / d f=2904 / 945=3.073, \mathrm{GFI}=0.529$, TLI $=0.672, \mathrm{CFI}=0.623$, RMSEA $=0.096$ and $\mathrm{SRMR}=0.0846$, with indices way inferior than the measurement model, confirming the absence of common method bias in the data set.

\subsection{Measurement model}

Structural equation modelling (SEM) was applied to estimate the conceptual model based on 227 cases. The two-step approach for structural equation modelling allows testing the measurement model first followed by the structural path model as suggested by Anderson and Gerbing (1988). Before CFA was undertaken, EFA was run to find the underlying factors generated from all the items (refer Appendix for EFA). CFA then confirmed the acceptability of the measurement model and the unidimensionality of the theoretical constructs as summarised in Table 2 (Bollen, 1989; Hair, Black, Babin, \& Anderson, 2014; Hu \& Bentler, 
1999). However, the chi-square value is found to be a poor model fit of data because of the associated $p$-value more than 0.05. Hair et al. (2014, p. 584), however, state that when the model contains over 30 measurement items and number of observed variables are fewer than 250, $p$ value less than $0.05(p<.05)$ is acceptable. Ideally $p$-value should be $>0.05$ for the model to be fit and accepted. Therefore, Bollen-Stine $p$-value was estimated through bootstrapping procedure that provided $p>0.194$ (i.e. more than $\mathrm{p}>0.05$ ) (Bollen \& Stine, 1992). Many previous studies have not reported $p$-value but appear to apply bootstrapping procedure in testing smaller samples to fit the model (Qrunfleh \& Tarafdar, 2014; Rai et al., 2006; Ralston, Blackhurst, Cantor, \& Crum, 2015). Therefore, we argue the model fit is acceptable. The model fit indices are: $\chi^{2}(930)=1366.876$, Bollen-Stine $\mathrm{p}=0.194, \chi^{2} / d f=1.255, \quad \mathrm{SRMR}=0.0451$, RMSEA $=0.034, C F I=0.962$ and TLI $=0.960$. The details of the factor loadings and $t$-values of CFA are presented in Table 2 .

\begin{tabular}{|c|c|c|c|}
\hline $\begin{array}{c}\text { Item } \\
\text { no }\end{array}$ & Measurement Item & $\begin{array}{c}\text { Factor } \\
\text { loading }\end{array}$ & t-value \\
\hline \multicolumn{4}{|c|}{ Construct 1: IoT capability } \\
\hline \multicolumn{4}{|c|}{ IoT has the capability in our supply chain: } \\
\hline 1.1 & To provide individual item level identification. & \multicolumn{2}{|c|}{ dropped in CFA } \\
\hline 1.2 & To provide unit level (e.g. container/box/pallet) identification. & 0.759 & $12.109^{*}$ \\
\hline 1.3 & $\begin{array}{l}\text { To monitor, track and trace supply chain entities and people through auto- } \\
\text { captured data. }\end{array}$ & 0.749 & $11.919^{*}$ \\
\hline 1.4 & $\begin{array}{l}\text { To measure supply chain activities, processes and its environmental } \\
\text { conditions. }\end{array}$ & 0.781 & A \\
\hline 1.5 & To help control supply chain processes remotely. & 0.718 & $11.323^{*}$ \\
\hline 1.6 & To make autonomous supply chain decisions. & \multicolumn{2}{|c|}{ dropped in CFA } \\
\hline 1.7 & To provide real-time information to optimise supply chain activities & 0.798 & $12.88^{*}$ \\
\hline 1.8 & To provide real-time intelligence of supply chain operations. & \multicolumn{2}{|c|}{ dropped in CFA } \\
\hline 1.9 & $\begin{array}{l}\text { To provide large volumes and variety of data to apply data analytics for tactical } \\
\text { and strategic decision making. }\end{array}$ & 0.767 & $12.26^{*}$ \\
\hline 1.10 & $\begin{array}{l}\text { To strengthen inter and intra organizational information sharing within the } \\
\text { supply chain. }\end{array}$ & 0.774 & $12.398^{*}$ \\
\hline 1.11 & $\begin{array}{l}\text { To facilitate inter and intra organizational decision making within the supply } \\
\text { chain. }\end{array}$ & \multicolumn{2}{|c|}{ dropped in CFA } \\
\hline 1.12 & To strengthen communication and coordination between operators. & \multicolumn{2}{|c|}{ dropped in CFA } \\
\hline \multicolumn{4}{|c|}{ Construct 2: Supplier integration } \\
\hline \multicolumn{4}{|c|}{ We have been able to improve the business processes with our suppliers to: } \\
\hline 2.1 & Improve information exchange with our suppliers. & 0.803 & $13.469^{*}$ \\
\hline 2.2 & Establish a quick ordering of inventory from our suppliers. & 0.798 & A \\
\hline 2.3 & $\begin{array}{l}\text { Accurately plan and adopt the procurement process in collaboration with our } \\
\text { suppliers. }\end{array}$ & \multicolumn{2}{|c|}{ dropped in CFA } \\
\hline 2.4 & Stabilize procurement with our suppliers. & 0.758 & $12.489^{*}$ \\
\hline 2.5 & Share real-time demand forecasts with our suppliers. & 0.721 & $11.71^{*}$ \\
\hline 2.6 & Improve strategic partnerships with our suppliers. & 0.758 & $12.478^{*}$ \\
\hline 2.7 & Help suppliers improve their processes to better meet our needs. & 0.738 & $12.057^{*}$ \\
\hline 2.8 & Improve the account payable processes for suppliers. & \multicolumn{2}{|c|}{ dropped in CFA } \\
\hline 2.9 & $\begin{array}{l}\text { Improve the transport/logistics processes of logistics partners to deliver orders } \\
\text { just in time. }\end{array}$ & 0.742 & $12.149^{*}$ \\
\hline
\end{tabular}




\begin{tabular}{|c|c|c|c|}
\hline 2.10 & Improve our receiving processes for delivered goods. & 0.762 & $12.581^{*}$ \\
\hline \multicolumn{4}{|c|}{ Construct 3: Internal integration } \\
\hline \multicolumn{4}{|c|}{ We have been able to improve our internal logistics processes to: } \\
\hline 3.1 & Improve the integration of data among internal functions. & \multicolumn{2}{|c|}{ dropped in CFA } \\
\hline 3.2 & Improve real-time communication and linkage among all internal functions. & 0.806 & $14.38^{*}$ \\
\hline 3.3 & $\begin{array}{l}\text { Accurately plan and adopt internal processes in collaboration with cross } \\
\text { functional teams. }\end{array}$ & 0.819 & $14.718^{*}$ \\
\hline 3.4 & Make and adopt demand forecasts in collaboration with cross functional teams. & 0.827 & A \\
\hline 3.5 & Improve inventory management in collaboration with cross functional teams. & \multicolumn{2}{|c|}{ dropped in CFA } \\
\hline 3.6 & Improve real-time searching of the inventory levels. & 0.808 & $14.433^{*}$ \\
\hline 3.7 & Improve real-time searching of logistics-related operating data. & 0.717 & $12.17^{*}$ \\
\hline 3.8 & Employ cross functional teams in process improvement. & 0.706 & $11.918^{*}$ \\
\hline 3.9 & Improve replenishment of shop floor shelves. & 0.766 & $13.343^{*}$ \\
\hline 3.10 & Reduce stock outs in the shop floor shelves. & 0.789 & $13.912^{*}$ \\
\hline \multicolumn{4}{|c|}{ Construct 4: Customer integration } \\
\hline \multicolumn{4}{|c|}{ We have been able to improve the business processes with our customers to: } \\
\hline 4.1 & Improve the strength of linkages with our customers. & 0.796 & $12.812^{*}$ \\
\hline 4.2 & Improve regular contacts with our customers. & 0.798 & $12.856^{*}$ \\
\hline 4.3 & Improve communication with our customers on products and promotions. & \multicolumn{2}{|c|}{ dropped in CFA } \\
\hline 4.4 & $\begin{array}{l}\text { Make and adopt demand forecasts with a real-time understanding of market } \\
\text { trends. }\end{array}$ & 0.778 & A \\
\hline 4.5 & $\begin{array}{l}\text { Improve the customer shopping experience/time/ordering/customising } \\
\text { processes. }\end{array}$ & 0.771 & $12.325^{*}$ \\
\hline 4.6 & $\begin{array}{l}\text { Accurately plan and adopt the checkout/dispatch/delivery processes through } \\
\text { a better understanding of market trends. }\end{array}$ & 0.759 & $12.082^{*}$ \\
\hline 4.7 & Improve the check-out/dispatch/delivery process of goods. & 0.739 & $11.693^{*}$ \\
\hline 4.8 & Improve and simplify the payment receivable process from our customers. & 0.734 & $11.606^{*}$ \\
\hline 4.9 & Improve customer feedback process. & \multicolumn{2}{|c|}{ dropped in CFA } \\
\hline \multicolumn{4}{|c|}{ Construct 5: Supply chain performance } \\
\hline \multicolumn{4}{|c|}{ We have been able to develop our supply chain processes to: } \\
\hline 5.1 & Improve product quality. & \multicolumn{2}{|c|}{ dropped in EFA } \\
\hline 5.2 & Improve supply chain delivery reliability. & \multicolumn{2}{|c|}{ dropped in CFA } \\
\hline 5.3 & Improve fill rates. & \multicolumn{2}{|c|}{ dropped in CFA } \\
\hline 5.4 & Improve perfect order fulfilment (deliveries with no errors). & 0.776 & A \\
\hline 5.5 & Improve supply chain flexibility (react to product changes, volume, mix). & 0.643 & $9.601^{*}$ \\
\hline 5.6 & Reduce the cash-to-cash cycle time. & 0.646 & $9.655^{*}$ \\
\hline 5.7 & Reduce the total supply chain management cost. & 0.74 & $11.24^{*}$ \\
\hline 5.8 & Reduce the cost of goods sold. & 0.764 & $11.665^{*}$ \\
\hline 5.9 & Improve value-added productivity (sales per employee). & 0.684 & $10.291^{*}$ \\
\hline \multicolumn{4}{|c|}{ Construct 6: Organisational performance } \\
\hline \multicolumn{4}{|c|}{ We been able to develop our organisational operations to: } \\
\hline 6.1 & Improve the product delivery cycle time. & 0.705 & $10.744^{*}$ \\
\hline 6.2 & Improve productivity (e.g. assets, operating costs, labour costs). & 0.719 & $10.981^{*}$ \\
\hline 6.3 & Improve sales of existing products. & 0.808 & $12.526^{*}$ \\
\hline 6.4 & Find new revenue streams. & \multicolumn{2}{|c|}{ dropped in CFA } \\
\hline 6.5 & Build strong and continuous bonds with customers. & 0.754 & A \\
\hline
\end{tabular}




\begin{tabular}{|l|l|l|l|}
6.6 & Gain precise knowledge of customer buying patterns. & 0.753 & $11.574^{*}$ \\
\hline 6.7 & Improve customer satisfaction. & 0.75 & $11.52^{*}$ \\
\hline 6.8 & Improve employee satisfaction. & 0.693 & $10.544^{*}$ \\
\hline 6.9 & Improve employee health and safety. & 0.703 & $10.723^{*}$ \\
\hline 6.10 & Reduce energy use. & 0.719 & $10.984^{*}$ \\
\hline 6.11 & Improve return/re-use/recycle. & dropped in CFA \\
\hline $\begin{array}{l}{ }^{*} \mathrm{p}<0.001 \\
{ }^{*} \mathrm{a}=\text { the loadings were set to unity to scale the latent variable }\end{array}$
\end{tabular}

Table 2: CFA Results of the measurement model4.4. Reliability and validity

Content validity of the questionnaire was confirmed by industry practitioners and academics prior to data collection. The unidimensionality of the theoretical constructs was confirmed by CFA test. The CFA results (Table 2) conclude that the measurement model is acceptable and its unidimensionality is confirmed (Byrne, 2013; Hair et al., 2014; Hu \& Bentler, 1999; Kline, 2015).

Reliability and validity of the constructs were tested post data collection by performing a series of analyses. The Cronbach's alpha and composite reliability of all constructs exceed the specified value 0.7 confirming the construct reliability (Hair et al., 2014; Huo, 2012). Cronbach's alpha values for all constructs were above 0.8 . The composite reliability values were strong at 0.75 and above. The highest correlation between constructs were 0.69 indicating no multicollinearity issues among the constructs (Hair et al., 2014).

The convergent validity of each measurement scale was assessed by CFA using the maximum likelihood approach (O'Leary-Kelly \& Vokurka, 1998). All indicators under respective constructs have statistically significant $(\mathrm{p}<0.001)$ factor loadings greater than 0.50 (Table 2$)$, which confirms convergent validity of the theoretical constructs (Anderson \& Gerbing, 1988; Zhao et al., 2011). Therefore, measurement items are significantly grouped to their underlying theoretical constructs. Further, the average variance extracted (AVE) of each construct exceeds the minimum value of 0.50 (Fornell \& Larcker, 1981) that suggests the constructs have sufficient convergent validity. Discriminant validity was evaluated by comparing the correlation between the construct and the square root of AVE. Referring Table 3, the square root of AVE of all the constructs shown along the diagonal is greater than the inter-construct correlation between any pair of them which shows the discriminant validity (Fornell \& Larcker, 1981). Table 3 also reports the means, standard deviations and inter-construct correlation coefficient. 


\begin{tabular}{|l|l|l|l|l|l|l|l|l|l|l|l|l|}
\hline Construct & $\begin{array}{l}\text { No. } \\
\text { of } \\
\text { items }\end{array}$ & IoT & SI & II & CI & SCP & FP & Mean & SD & $\begin{array}{l}\text { Cr. } \\
\text { Alpha }\end{array}$ & CR & AVE \\
\hline & & & & & & & & & & & & \\
\hline IoT capability & 7 & 0.76 & & & & & & 4.82 & 1.27 & 0.91 & 0.86 & 0.58 \\
\hline $\begin{array}{l}\text { Supplier } \\
\text { integration }\end{array}$ & 8 & 0.63 & 0.76 & & & & & 4.72 & 1.32 & 0.92 & 0.86 & 0.58 \\
\hline $\begin{array}{l}\text { Internal } \\
\text { integration }\end{array}$ & 8 & 0.64 & 0.70 & 0.78 & & & & 4.50 & 1.37 & 0.93 & 0.87 & 0.61 \\
\hline $\begin{array}{l}\text { Customer } \\
\text { integration }\end{array}$ & 7 & 0.59 & 0.64 & 0.69 & 0.77 & & & 4.72 & 1.33 & 0.91 & 0.85 & 0.59 \\
\hline $\begin{array}{l}\text { Supply chain } \\
\text { performance }\end{array}$ & 8 & 0.66 & 0.63 & 0.63 & 0.60 & 0.71 & & 4.65 & 1.45 & 0.86 & 0.75 & 0.51 \\
\hline $\begin{array}{l}\text { Organisational } \\
\text { performance }\end{array}$ & 9 & 0.65 & 0.60 & 0.58 & 0.62 & 0.62 & 0.73 & 4.44 & 1.41 & 0.91 & 0.84 & 0.54 \\
\hline
\end{tabular}

The diagonal values represent the square root of AVE extracted for each construct $C R=$ Composite reliability; $C r$. Alpha=Cronbach's alpha; $S D=$ Standard deviation All correlation coefficients below the diagonal are significant at $p<.001$

Table 3: Descriptive statistics, Reliability (Cronbach alpha and composite) and discriminant validity tests

\subsection{Structural path model and hypotheses testing}

Figure 2 and Table 4 present the results of structural path model using AMOS 23 (Hair et al., 2014; Hu \& Bentler, 1999). Bootstrapping was used to generate the p-statistic with 227 cases (Qrunfleh \& Tarafdar, 2014; Ralston et al., 2015). The structural model resulted in overall acceptable fit with $\chi^{2}(936)=1236.586$, Bollen-Stine $\mathrm{p}=0.095, \chi^{2} / \mathrm{df}=1.321, \quad \mathrm{SRMR}=0.0761$, RMSEA $=0.038, C F I=0.952$ and TLI $=0.949$. All the goodness-of-fit indices are above or close to the recommended cut-off points, suggesting that the specified model adequately captures the hypothesised relationship among all constructs. The findings therefore validate the proposed theoretical model.

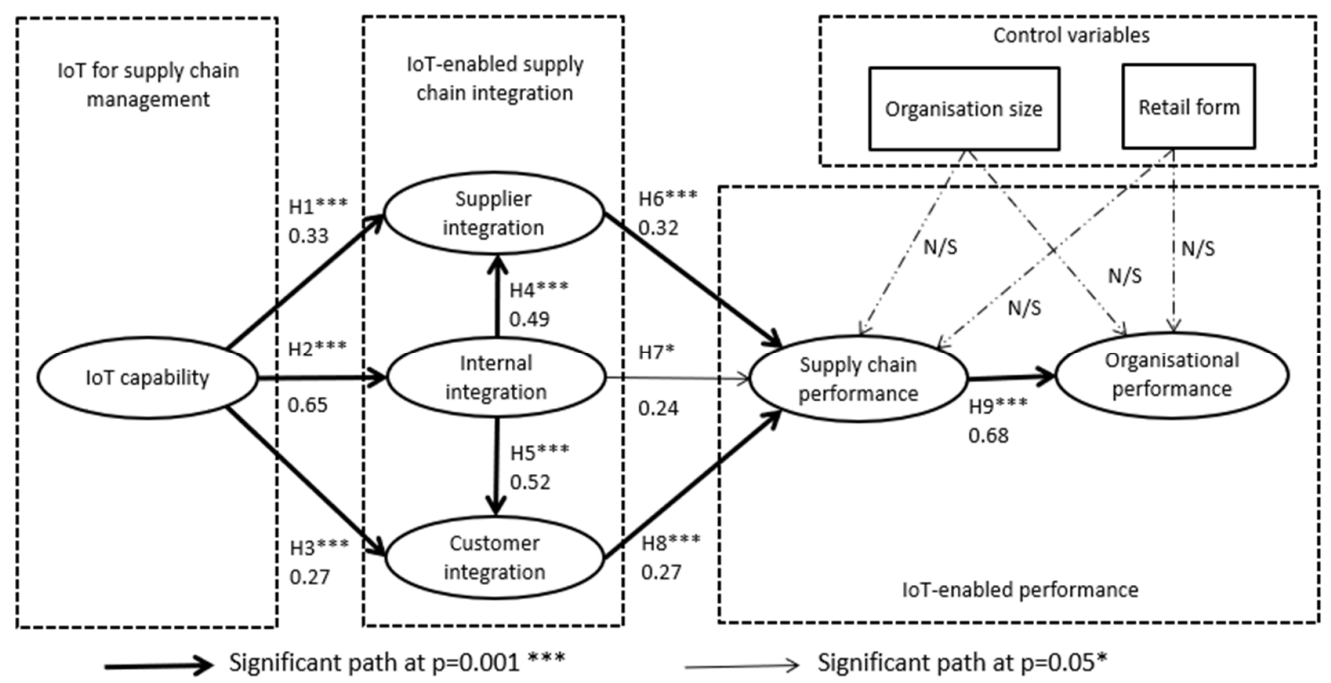

Figure 2: A conceptual framework for IoT-enabled supply chain integration and performance 
The nine hypotheses are supported as shown in Table 4. The standardised beta coefficients of the path along with the t-statistics are also presented.

\begin{tabular}{|l|l|c|c|c|}
\hline Hypotheses & Path & Std. $\mathbf{B}$ & t-values & Results \\
\hline & & & & \\
\hline H1 & IoT capability $\rightarrow$ Supplier integration & $0.33^{* *}$ & 4.299 & Supported \\
\hline H2 & IoT capability $\rightarrow$ Internal integration & $0.65^{* *}$ & 6.285 & Supported \\
\hline H3 & IoT capability $\rightarrow$ Customer integration & $0.27^{* *}$ & 3.450 & Supported \\
\hline H4 & Internal integration $\rightarrow$ Supplier integration & $0.49^{* *}$ & 6.285 & Supported \\
\hline H5 & Internal integration $\rightarrow$ Customer integration & $0.52^{* *}$ & 6.374 & Supported \\
\hline H6 & Supplier integration $\rightarrow$ Supply chain performance & $0.32^{* *}$ & 3.726 & Supported \\
\hline H7 & Internal integration $\rightarrow$ Supply chain performance & $0.24^{*}$ & 2.349 & Supported \\
\hline H8 & Customer integration $\rightarrow$ Supply chain performance & $0.27^{* *}$ & 3.188 & Supported \\
\hline H9 & $\begin{array}{l}\text { Supply chain performance } \rightarrow \text { Organisational } \\
\text { performance }\end{array}$ & $0.68^{* *}$ & 8.520 & Supported \\
\hline
\end{tabular}

${ }^{* *}<0.001,{ }^{*} \mathrm{p}<0.05$

Table 4: Results of the structural path analysis

The results confirm the hypothesised relationships among the constructs in the theoretical framework, suggesting that IoT-enabled supply chain integration has a positive and significant effect on supply chain performance, that in turn impacts positively on organisational performance. IoT capability has a positive and significant effect on three dimensions of supply chain integration processes confirming the acceptance of $\mathrm{H} 1, \mathrm{H} 2$, and H3. Also, IoT-enabled internal integration is positively and significantly related to IoT-enabled supplier and customer integration process confirming the acceptance of $\mathrm{H} 4$ and $\mathrm{H} 5$. The findings show that IoT-enabled supplier-, internal- and customer integration are positively and significantly related to supply chain performance confirming the acceptance of H6, H7, and H8. Hypothesis H9 is confirmed too when IoT-enabled supply chain performance is found to be positively associated with organisational performance.

\subsubsection{Testing for control variables}

The results indicated that organisation size has no significant effect on IoT-enabled supply chain performance $(\beta=0.167, t=1.521, p=0.128)$ or IoT-enabled organisational performance $(\beta$ $=0.104, t=0.968, p=0.333$ ) of retail organisations. Likewise, the retail form also did not exhibit a significant effect on IoT-enabled supply chain performance $(\beta=0.058, t=0.881, p=0.378)$ or IoT-enabled organisational performance $(\beta=0.09, t=1.397, p=0.162)$. Therefore, the two control variables were not found to be significant.

\subsubsection{The post hoc analysis}

A post hoc analysis was conducted to verify if any model re-specification was desirable. IoT is perceived to help supply chain operations (Atzori et al., 2010). Thus, a direct link between IoT capability and supply chain performance was drawn and analysed. The alternative model with a direct path between IoT capability and supply chain performance was found significant $(\beta=$ $0.379, t=4.440, p<0.001)$. However, the relationships between IoT-enabled supplier integration and IoT-enabled customer integration with supply chain performance (i.e. H6 and H8) were found to be weaker and IoT-enabled internal integration and supply chain performance (H7) 
was found insignificant $(\beta=0.139, t=1.419, p=0.156)$. We, therefore, decline to accept this changed path relationship following the theory that IoT should have a positive effect on internal, supplier and customer integration to influence supply chain performance (Li et al., 2009; Rai et al., 2006). So, the competing model was overruled. The post hoc analysis concluded that model re-specification was not feasible.

\section{Discussion and Implications}

The empirical findings of this study show that IoT-enabled integration is perceived to improve the performance of supply chain as well as organisations. IoT adoption is found to have significant effect on three dimensions of integration namely suppliers, internal and customers. The IoT paradigm that includes physical objects such as sensors, actuators, palm-held devices and smart phone has the capability of external integration (i.e. suppliers and customers) as well as internal integration (i.e. cross-functional operations) enabling information capture, sharing, communication and inter-firm relationships. Drawing on the emerging IoT-enabled organisational capability perspective, we suggest that retailers those who leverage on IoT for supply chain integration capability can yield significant and sustained performance improvement. The IoT-powered digital infrastructure enables the retailers to develop a higherorder capability of supply chain integration among partners (e.g. suppliers and customers). This capability enables retailers to capture, share and analyse demand information of customers and their preference of products and services. It helps integrate suppliers for their product information and delivery schedule. While inter-functional integration within the organisations will reap the benefit of IoT capability, it brings more benefits to the organisations by integrating their customers and the suppliers, as perceived by the sample respondents.

The results reveal that IoT capability affects supply chain integration positively which is consistent with many earlier studies on ICT-enabled digital integration (Li et al., 2009; Rai et al., 2006; Yu, 2015). Co-existence of IoT functional capability along with ICT capability of organisations is perceived to add integration capability. IoT is viewed as added components to the exiting ICT technologies to make them proficient in data capture and information sharing. The finding supports the organisational capability theory perspective in a way that an organisation with a high level of internal communication and coordination capabilities is more capable of achieving a high level of external integration capabilities (Zhao et al., 2011). While scholars have conceptualised IoT adoption as more of rhetoric in supply chain operations in general (Atzori et al., 2010; Borgia, 2014; Zhou, Chong, \& Ngai, 2015) and retail supply chains in specific (Lee \& Lee, 2015; Yu et al., 2015), this research reinforces further that IoT adoption strategy can improve supply chain process integration, and in turn supply chain performance and organisational performance.

While conceptualising the IoT-enabled integration capability in supply chain, the study contributes theoretically into supply chain integration literature as well as IS literature. While IS literature focuses predominantly on emerging technologies such as IoT, cloud and automation initiative, supply chain integration literature focus is primarily on their effective applications in logistics processes around suppliers, customers and internal functions. It extends the prior literature abounds with ICT-enabled process integration to deliver the supply chain performance benefits (Li et al., 2009; Rai et al., 2006; Vanpoucke et al., 2017; Yu, 2015), the literature is however, they are deficient in embracing any emerging technology that will bring in added advantages in the integration mechanism. Here we refer to IoT as an emerging but ever pervasive technology that uses sensors, devices with short range radio 
frequency, smart mobile phones, actuators etc. with the capability to capture and share data online through Internet. Earlier studies have provided no empirical evidence of these IoTs in supply chain integration context. Literature have argued IoT more of a pervasive technology per se by focusing on vision, features, and likely applications (Atzori et al., 2010; Borgia, 2014; Mishra et al., 2016; Whitmore et al., 2014). The literature claim IoT as having a capability to connect physical things with digital world, and argue that the 'things' can be read, recognised, located, addressed and controlled by using Internet (Borgia, 2014). Our results indicate that IoT adoption is positively connected to supply chain process integration of internal functions, supplier processes and customer processes. The integration thus achieved is likely to have positive influences on supply chain performance and organisational performance.

This study incorporates the emerging IoT adoption as an organisational capability which has not been studied previously in the domain of supply chain integration. From an organisational capability theory perspective, which is related to resource-based view, supply chain integration is a capability of organisations having IoT technologies as organisational resources (Rai et al., 2006). Like ICT-enabled integration affecting positively on supply chain performance (Li et al., 2009; Rai et al., 2006; Yu, 2015), adoption and deployment of IoT per se is perceived, in this study, to have positive influence on performance. Aside, Bharadwaj (2000) argues ICT investment is to be coupled up with other resources like human and financial resources to gain competitive advantage (Armstrong \& Shimizu, 2007; Newbert, 2007). We argue in similar vein for IoT investment that will complement the current ICT capabilities in significant way. The perceived integration capability can improve the performance of supply chain, as well as firm sustainability. Further, the findings reinforce several IoT related conceptual discussions (Ng et al., 2015; Ping et al., 2011) and laboratory-based study outcomes (Reaidy et al., 2015; Yan et al., 2014) that corroborates its positive impact.

The study addressed an important shortfall by conducting an empirical research in the area of the emerging IoT applications in supply chain integration. While literature is conceptual and rhetoric about its business applications, this study has taken IoT aboard in an empirical framework to see its significant effects on performance improvement. It can be argued that while IoT plays a vital role on top of the current ICT legacy systems in internal operations, it can be deployed to enhance positive performance outcomes further by connecting digitally the globally spread smart objects and customers through Internet. While ICT connects end to end computers globally over Internet, IoT can increase the reach by connecting smart objects to computers and other objects to capture data.

Practically, the results are beneficial to the managers in a transition to IoT adoption. Our findings will encourage investments on IoT to complement ICT capabilities currently in place. IoT emerges as a relatively new sphere of study with majority of scholars still focus on development of technology per se, and its service architecture aspect (Liu \& Gao, 2014; Whitmore et al., 2014). However, the business application purview of IoT from the supply chain perspective is yet to enter the mainstream research (Mishra et al., 2016). This is the gap in current research in supply chain domain. While most retailers have some form of ICT technologies (e.g. bar code, EDI, WMS) as their current capability, they need to acquire, integrate, reconfigure, and release resources to upgrade with the emerging IoT technologies (e.g. RFID, sensors, palm-held devices, smart phones). Retail managers will see these sensors and smart devices helping capture ample data from the things/objects in retail points. Aligning IoT adoption along with supply chain strategy is likely to improve the supply chain and firm 
performance (Qrunfleh \& Tarafdar, 2014). The findings inform managers about IoT capabilities as an extension in the long established digitally-enabled supply chain integration capability. For example, the deployment of palm-held smart electronic devices assists in autocapturing more crucial data around logistics helping mangers to explore analytics of these data. As data analytics gaining popularity for effective decision using quality data, firms increasingly find value in data-driven decision. IoT adoption and deployment into logistics functions within the retail organisations will certainly benefit in their day to day operations. The key insight is that managers should develop IoT- capability alongside existing ICT capability to achieve sustainable competitive advantage.

The results suggest that retail managers need to first establish internal integration within the internal functions while they go out for external integration with their customers or suppliers. As IoT-enabled supplier- and customer integration affects supply chain performance more significantly than IoT-enabled internal integration, in contrast to general consensus (Ataseven \& Nair, 2017; Yu, 2015). It can be argued that IoT-enabled external integration is related at a higher significance for supply chain performance gains beyond firm boundaries due to IoT's pervasiveness and omnipresent ability. Retail managers should stretch their focus from retail management perspective to the entire supply chain to include suppliers and customers. Further, they need to consider linking existing IoT devices with suppliers (e.g. GPS) and customers (e.g. smart phones), mustering all digital data into one Internet-based platform to share, communicate and process information from each other. This unified supply chain system approach may derive greater benefits for all partners fulfilling the conceptual objective of IoT platform to establishing a dynamic worldwide network (Borgia, 2014).

The findings also contribute to policy making by providing evidence that the investment in IoT is a sound public investment. Various developed and developing countries have pursued national strategies on IoT technology deployment and allocated substantial funding on IoT research. The findings may help advocate IoT to be lifted to the national strategy for Australian businesses, shadowing US, EU, China, Korea and Japan (Borgia, 2014).

\section{Conclusion and limitations}

IoT has emerged as an innovative technology with capabilities to improve supply chain information flow. However, the effect of IoT on supply chain integration and in turn performance is not yet explored empirically. The survey-based cross-sectional study reveals a positive and significant relationship between IoT adoption and the effect it can have on supplier, customers and internal supply chain functions of retail firms. Co-existence of IoT capability in combination with ICT capability is perceived to have a significant improvement in supply chain as well as sustainable firm performance. This study contributes to the supply chain integration literature over and above the contribution by generic ICT driven digitally enabled supply chain integration significantly associated with supply chain performance and in turn the performance of the retail firm. From organisational capability theory perspective, the adoption of IoT helps achieving organisational integration capability.

There are some limitations acknowledged in this study. First, the study sampled Australian retailers across industries thereby limiting its generalisability with caution for retailers in the pacific region. The study holds good in Australian context with relatively robust Internet network and more recently with national broadband network (NBN). The future study can undertake a research whether this framework can be validated in other setting within the 
pacific regions where the Internet technology is relatively poor. The smaller sample size $(n=227)$ did not allow a sector-specific analysis of IoT adoption to reveal its effect on integration mechanism and performance. Future research with larger sample can undertake a comparative study to reveal more of each sector. Adoption of emerging technology is attributed to institutional pressure from stakeholders such as suppliers, customers and local government (Teo \& Pok, 2003). The future research needs to consider institutional pressure as a moderator to test its influence on the relationship between IoT-enabled process integration and supply chain performance. The cross-sectional study was undertaken with the retailers at a point of time that excluded the views of the suppliers and customers. The future study can include the supply chain partners to get a more meaningful opinion about IoT adoption in improving the organisational performance. Also, we suggest that a longitudinal study along the time gap of three years may validate the perceptual findings of this study. The study also lacks descriptive information thus an in-depth interview-based study in future may explain the findings of this cross-sectional study.

\section{Acknowledgement}

We acknowledge all the reviewers and editors for their valuable suggestion to improve the quality of paper.

\section{References}

ABS Retail industry analysis. (2014). Retail and Wholesale Industries, Australia,. Retrieved from http://www.abs.gov.au/ausstats/abs@.nsf/Latestproducts/8622.0Main\%20Features32012 -13 ? opendocument\&tabname $=$ Summary\&prodno=8622.0\&issue=2012-

$13 \&$ num $=\&$ view $=$

Alfalla-Luque, R., Medina-Lopez, C., \& Dey, P. K. (2013). Supply chain integration framework using literature review. Production Planning \& Control, 24(8-9), 800-817.

Anderson, J. C., \& Gerbing, D. W. (1988). Structural equation modeling in practice: A review and recommended two-step approach. Psychological bulletin, 103(3), 411.

Armstrong, C. E., \& Shimizu, K. (2007). A review of approaches to empirical research on the resource-based view of the firm. Journal of management, 33(6), 959-986.

Armstrong, J. S., \& Overton, T. S. (1977). Estimating nonresponse bias in mail surveys. Journal of marketing research, 396-402.

Ataseven, C., \& Nair, A. (2017). Assessment of supply chain integration and performance relationships: A meta-analytic investigation of the literature. International Journal of Production Economics, 185, 252-265.

Atzori, L., Iera, A., \& Morabito, G. (2010). The Internet of Things: A survey. Computer Networks, 54(15), 2787-2805.

Baltar, F., \& Brunet Icart, I. (2011). The use of Facebook in social research. The virtual snowball method applied to the study of immigrants entrepreneurs in Spain: Centro de Documentación, Facultad de Ciencias Económicas y Sociales, Universidad Nacional de Mar del Plata. 
Baltar, F., \& Brunet Icart, I. (2012). Social research 2.0: virtual snowball sampling method using Facebook: Centro de Documentación, Facultad de Ciencias Económicas y Sociales, Universidad Nacional de Mar del Plata.

Ben-Daya, M., Hassini, E., \& Bahroun, Z. (2017). Internet of things and supply chain management: a literature review. International Journal of Production Research, 1-24.

Bharadwaj, A. S. (2000). A resource-based perspective on information technology capability and firm performance: an empirical investigation. MIS quarterly, 169-196.

Bollen, K., \& Stine, R. A. (1992). Bootstrapping goodness-of-fit measures in structural equation models. Sociological Methods \& Research, 21(2), 205-229.

Bollen, K. A. (1989). A new incremental fit index for general structural equation models. Sociological Methods E Research, 17(3), 303-316.

Borgia, E. (2014). The Internet of Things vision: Key features, applications and open issues. Computer Communications, 54, 1-31.

Byrne, B. M. (2013). Structural equation modeling with AMOS: Basic concepts, applications, and programming: Routledge.

Carter, C. R., \& Rogers, D. S. (2008). A framework of sustainable supply chain management: moving toward new theory. International Journal of Physical Distribution $\mathcal{E}$ Logistics Management, 38(5), 360-387.

Christopher, M. (2016). Logistics \& supply chain management: Pearson UK.

Christopher, M., Crum, M., \& Holweg, M. (2011). “Supply Chain 2.0”: managing supply chains in the era of turbulence. International Journal of Physical Distribution \& Logistics Management, 41(1), 63-82.

Christopher, M., \& Towill, D. (2001). An integrated model for the design of agile supply chains. International Journal of Physical Distribution E Logistics Management, 31(4), 235-246.

Constantinides, E., Kahlert, M., \& de Vries, S. A. (2017). The relevance of technological autonomy in the acceptance of IoT services in retail. Paper presented at the 2 nd International Conference on Internet of Things, Data and Cloud Computing, ICC 2017.

DHL. (2015). Internet of Things in Logistics. Retrieved from DHL Trend Research: http://www.dhl.com/en/about_us/logistics_insights/dhl_trend_research/internet_of_thi ngs.html\#.Ve_EMpdSLuU

Dillman, D. A. (2011). Mail and Internet surveys: The tailored design method--2007 Update with new Internet, visual, and mixed-mode guide. New York: John Wiley \& Sons.

Dolbier, C. L., Webster, J. A., McCalister, K. T., Mallon, M. W., \& Steinhardt, M. A. (2005). Reliability and validity of a single-item measure of job satisfaction. American Journal of Health Promotion, 19(3), 194-198.

Dubey, R., Gunasekaran, A., Childe, S. J., Papadopoulos, T., \& Wamba, S. F. (2017). World class sustainable supply chain management: critical review and further research directions. The International Journal of Logistics Management, 28(2), 332-362.

Edwards, C., \& Hopkins, J. (2018). The Australian supply chain tech survey. Retrieved from https://sclaa.com.au/2018-australian-supply-chain-tech-survey-results 
Elkington, J. (1997). Cannibals with forks. The triple bottom line of 21st century.

Ellram, L. M., \& Cooper, M. C. (1993). Characteristics of supply chain management and the implications for purchasing and logistics strategy. The International Journal of Logistics Management, 4(2), 13-24.

Fabbe-Costes, N., \& Jahre, M. (2008). Supply chain integration and performance: a review of the evidence. The International Journal of Logistics Management, 19(2), 130-154.

Fleisch, E., \& Tellkamp, C. (2005). Inventory inaccuracy and supply chain performance: a simulation study of a retail supply chain. International Journal of Production Economics, 95(3), 373-385.

Flynn, B. B., Huo, B., \& Zhao, X. (2010). The impact of supply chain integration on performance: A contingency and configuration approach. Journal of Operations Management, 28(1), 58-71.

Fornell, C., \& Larcker, D. F. (1981). Evaluating structural equation models with unobservable variables and measurement error. Journal of marketing research, 39-50.

Frohlich, M. T., \& Westbrook, R. (2001). Arcs of integration: an international study of supply chain strategies. Journal of Operations Management, 19(2), 185-200.

Gunasekaran, A., Patel, C., \& McGaughey, R. E. (2004). A framework for supply chain performance measurement. International Journal of Production Economics, 87(3), 333-347.

Haddud, A., DeSouza, A., Khare, A., \& Lee, H. (2017). Examining potential benefits and challenges associated with the Internet of Things integration in supply chains. Journal of Manufacturing Technology Management, 28(8), 1055-1085.

Hair, J. F., Black, W. C., Babin, B. J., \& Anderson, R. E. (2014). Multivariate data analysis (Vol. 7): Pearson Upper Saddle River, NJ.

Ho, D. C. K., Au, K. F., \& Newton, E. (2002). Empirical research on supply chain management: A critical review and recommendations. International Journal of Production Research, 40(17), 4415-4430.

Hofmann, E., \& Rüsch, M. (2017). Industry 4.0 and the current status as well as future prospects on logistics. Computers in Industry, 89, 23-34.

Hu, L. T., \& Bentler, P. M. (1999). Cutoff criteria for fit indexes in covariance structure analysis: Conventional criteria versus new alternatives. Structural Equation Modeling: A Multidisciplinary Journal, 6(1), 1-55.

Huh, S., Yook, K.-H., \& Kim, I.-w. (2008). Relationship between organizational capabilities and performance of target costing: an empirical study of Japanese companies. Journal of International Business Research, 7(1), 91.

Huo, B. (2012). The impact of supply chain integration on company performance: an organizational capability perspective. Supply Chain Management: An International Journal, 17(6), 596-610.

Kahlert, M., Constantinides, E., \& de Vries, S. (2017). The relevance of technological autonomy in the customer acceptance of IoT services in retail. Paper presented at the Proceedings of the Second International Conference on Internet of things and Cloud Computing, Cambridge, United Kingdom. 
Kim, S. W. (2009). An investigation on the direct and indirect effect of supply chain integration on firm performance. International Journal of Production Economics, 119(2), 328-346.

Kline, R. B. (2015). Principles and practice of structural equation modeling (Vol. 4th edtion): The Guilford Press.

Kusunoki, K., Nonaka, I., \& Nagata, A. (1998). Organizational capabilities in product development of Japanese firms: a conceptual framework and empirical findings. Organization science, 9(6), 699-718.

Lee, I., \& Lee, K. (2015). The Internet of Things (IoT): Applications, investments, and challenges for enterprises. Business Horizons, 58(4), 431-440.

Li, G., Yang, H., Sun, L., \& Sohal, A. S. (2009). The impact of IT implementation on supply chain integration and performance. International Journal of Production Economics, 120(1), 125-138.

Liu, W., \& Gao, Z. (2014). Study on IOT based architecture of logistics service supply chain. International Journal of Grid and Distributed Computing, 7(1), 169-178.

Liu, X., \& Sun, Y. (2011). Information Flow Management of Vendor-Managed Inventory System in Automobile Parts Inbound Logistics Based on Internet of Things. Journal of Software, 6(7), 1374-1380.

Lorenzoni, G., \& Lipparini, A. (1999). The leveraging of interfirm relationships as a distinctive organizational capability: a longitudinal study. Strategic Management Journal, 317-338.

Mattern, F., \& Floerkemeier, C. (2010). From the Internet of Computers to the Internet of Things From active data management to event-based systems and more (pp. 242-259): Springer.

Mishra, D., Gunasekaran, A., Childe, S. J., Papadopoulos, T., Dubey, R., \& Wamba, S. F. (2016). Vision, applications and future challenges of Internet of Things. Industrial Management E Data Systems, 116(7), 1331-1355.

Näslund, D., \& Hulthen, H. (2012). Supply chain management integration: a critical analysis. Benchmarking: An International Journal, 19(4/5), 481-501.

Newbert, S. L. (2007). Empirical research on the resource-based view of the firm: an assessment and suggestions for future research. Strategic Management Journal, 28(2), 121-146.

Ng, I., Scharf, K., Pogrebna, G., \& Maull, R. (2015). Contextual variety, Internet-of-Things and the choice of tailoring over platform: Mass customisation strategy in supply chain management. International Journal of Production Economics, 159(1), 76-87.

O'Leary-Kelly, S. W., \& Vokurka, R. J. (1998). The empirical assessment of construct validity. Journal of Operations Management, 16(4), 387-405.

Paulraj, A. (2011). Understanding the relationships between internal resources and capabilities, sustainable supply management and organizational sustainability. Journal of Supply Chain Management, 47(1), 19-37.

Perera, C., Member, C. H. L., Jayawardena, S., \& Chen, M. (2015). Context-aware Computing in the Internet of Things: A Survey on Internet of Things From Industrial Market Perspective. IEEE Access, 2(1ng), 1660-1679. 
Ping, L., Liu, Q., Zhou, Z., \& Wang, H. (2011). Agile supply chain management over the internet of things. Paper presented at the Management and Service Science (MASS), 2011 International Conference on 2011 Aug 12.

Podsakoff, P. M., MacKenzie, S. B., Lee, J.-Y., \& Podsakoff, N. P. (2003). Common method biases in behavioral research: a critical review of the literature and recommended remedies. Journal of applied psychology, 88(5), 879.

Qrunfleh, S., \& Tarafdar, M. (2014). Supply chain information systems strategy: Impacts on supply chain performance and firm performance. International Journal of Production Economics, 147(1), 340-350.

Rai, A., Patnayakuni, R., \& Seth, N. (2006). Firm performance impacts of digitally enabled supply chain integration capabilities. MIS quarterly, 30(2), 225-246.

Ralston, P. M., Blackhurst, J., Cantor, D. E., \& Crum, M. R. (2015). A Structure-ConductPerformance Perspective of How Strategic Supply Chain Integration Affects Firm Performance. Journal of Supply Chain Management, 51(2), 47.

Reaidy, P. J., Gunasekaran, A., \& Spalanzani, A. (2015). Bottom-up approach based on Internet of Things for order fulfillment in a collaborative warehousing environment. International Journal of Production Economics, 159(1), 29-40.

Schoenherr, T., \& Swink, M. (2012). Revisiting the arcs of integration: Cross-validations and extensions. Journal of Operations Management, 30(1), 99-115.

Seuring, S., \& Müller, M. (2008). From a literature review to a conceptual framework for sustainable supply chain management. Journal of Cleaner Production, 16(15), 1699-1710.

Spekman, R. E., Kamauff Jr, J. W., \& Myhr, N. (1998). An empirical investigation into supply chain management: a perspective on partnerships. Supply Chain Management: An International Journal, 3(2), 53-67.

Souders, Andy (2015). From Desert Storm to the retail store: Five technologies that are closing global supply chain gaps, Retreived from http://www.supplychainquarterly.com/topics/technology/20151228-fivetechnologies-that-are-closing-global-supply-chain-gaps/ on 20 May 2018.

Teo, T. S., \& Pok, S. H. (2003). Adoption of WAP-enabled mobile phones among Internet users. Omega, 31(6), 483-498.

Trappey, A. J. C., Trappey, C. V., Hareesh Govindarajan, U., Chuang, A. C., \& Sun, J. J. (2017). A review of essential standards and patent landscapes for the Internet of Things: A key enabler for Industry 4.0. Advanced Engineering Informatics, 33, 208-229.

Tu, M. (2018). An exploratory study of Internet of Things (IoT) adoption intention in logistics and supply chain management-a mixed research approach. International Journal of Logistics Management, The(just-accepted), 00-00.

Uckelmann, D., Harrison, M., \& Michahelles, F. (2011). An architectural approach towards the future Internet of Things Architecting the internet of things (pp. 1-24): Springer-Verlag Berlin Heidelberg. 
Vanpoucke, E., Vereecke, A., \& Muylle, S. (2017). Leveraging the impact of supply chain integration through information technology. International Journal of Operations $\mathcal{E}$ Production Management, 37(4), 510-530.

Verdouw, C. N., Wolfert, J., Beulens, A. J. M., \& Rialland, A. (2016). Virtualization of food supply chains with the internet of things. Journal of Food Engineering, 176, 128-136.

Verona, G. (1999). A resource-based view of product development. Academy of Management Review, 24(1), 132-142.

Wasserman, M., \& Mahmoodi, F. (2017). Disruptive technologies: Should you give them the green light? Retrieved from http://www.supplychainquarterly.com/topics/Technology/20170302disruptive-technologies-should-you-give-them-the-green-light/ on 20 May 2018.

Weber, R. H. (2009). Internet of things-Need for a new legal environment? Computer law $\mathcal{E}$ security review, 25(6), 522-527.

Whitmore, A., Agarwal, A., \& Da Xu, L. (2014). The Internet of Things-A survey of topics and trends. Information Systems Frontiers, 17(2), 261-274.

Xu, L. D., He, W., \& Li, S. (2014). Internet of Things in industries: A survey. Industrial Informatics, IEEE Transactions on, 10(4), 2233-2243.

Yan, J., Xin, S., Liu, Q., Xu, W., Yang, L., Fan, L., . . Wang, Q. (2014). Intelligent supply chain integration and management based on Cloud of Things. International Journal of Distributed Sensor Networks, 10(3), 1-15.

YellowPages. (2016). Australian Business Directory https://www.yellowpages.com.au/, retrieved on 14 December 12017.

Yu, J., Subramanian, N., Ning, K., \& Edwards, D. (2015). Product delivery service provider selection and customer satisfaction in the era of internet of things: A Chinese e-retailers' perspective. International Journal of Production Economics, 159(1), 104-116.

Yu, W. (2015). The effect of IT-enabled supply chain integration on performance. Production Planning E Control, 26(12), 945-957.

Yu, W., Jacobs, M. A., Salisbury, W. D., \& Enns, H. (2013). The effects of supply chain integration on customer satisfaction and financial performance: An organizational learning perspective. International Journal of Production Economics, 146(1), 346-358.

Zhao, X., Huo, B., Selen, W., \& Yeung, J. H. Y. (2011). The impact of internal integration and relationship commitment on external integration. Journal of Operations Management, 29(1), 17-32.

Zhou, K., Liu, T., \& Zhou, L. (2015). Industry 4.0: Towards future industrial opportunities and challenges. Paper presented at the Fuzzy Systems and Knowledge Discovery (FSKD), 2015 12th International Conference on.

Zhou, L., Chong, A. Y. L., \& Ngai, E. W. T. (2015). Supply chain management in the era of the internet of things. International Journal of Production Economics, 159(1), 1-3. 
Zhu, Q., Sarkis, J., \& Lai, K.-h. (2012). Examining the effects of green supply chain management practices and their mediations on performance improvements. International Journal of Production Research, 50(5), 1377-1394. 


\section{Appendix}

Table: EFA Results of the measurement model

\begin{tabular}{|c|c|c|c|}
\hline $\begin{array}{l}\text { Item } \\
\text { No }\end{array}$ & Measurement Item & $\begin{array}{l}\text { Factor } \\
\text { loading }\end{array}$ & $\begin{array}{l}\text { Variance } \\
\text { explained }\end{array}$ \\
\hline \multicolumn{4}{|c|}{ Construct 1: IoT capability } \\
\hline \multicolumn{4}{|c|}{ IoT has the capability in our supply chain: } \\
\hline 1.1 & To provide individual item level identification. & 0.669 & $57 \%$ \\
\hline 1.2 & To provide unit level (e.g. container/box/pallet) identification. & 0.779 & \\
\hline 1.3 & $\begin{array}{l}\text { To monitor, track and trace supply chain entities and people through auto- } \\
\text { captured data. }\end{array}$ & 0.732 & \\
\hline 1.4 & $\begin{array}{l}\text { To measure supply chain activities, processes and its environmental } \\
\text { conditions. }\end{array}$ & 0.770 & \\
\hline 1.5 & To help control supply chain processes remotely. & 0.705 & \\
\hline 1.6 & To make autonomous supply chain decisions. & 0.577 & \\
\hline 1.7 & To provide real-time information to optimise supply chain activities & 0.799 & \\
\hline 1.8 & To provide real-time intelligence of supply chain operations. & 0.620 & \\
\hline 1.9 & $\begin{array}{l}\text { To provide large volumes and variety of data to apply data analytics for } \\
\text { tactical and strategic decision making. }\end{array}$ & 0.788 & \\
\hline 1.10 & $\begin{array}{l}\text { To strengthen inter and intra organizational information sharing within the } \\
\text { supply chain. }\end{array}$ & 0.743 & \\
\hline 1.11 & $\begin{array}{l}\text { To facilitate inter and intra organizational decision making within the supply } \\
\text { chain. }\end{array}$ & 0.750 & \\
\hline 1.12 & To strengthen communication and coordination between operators. & 0.783 & \\
\hline \multicolumn{4}{|c|}{ Eigenvalue $=6.839 ; \mathrm{KMO}=0.942 ;$ Bartlett's test of sphericity: $\mathrm{x}^{2}=1614.476, \mathrm{p}<0.001$} \\
\hline \multicolumn{4}{|c|}{ Construct 2: Supplier integration } \\
\hline \multicolumn{4}{|c|}{ We have been able to improve the business processes with our suppliers to: } \\
\hline 2.1 & Improve information exchange with our suppliers. & 0.775 & $60 \%$ \\
\hline 2.2 & Establish a quick ordering of inventory from our suppliers. & 0.791 & \\
\hline 2.3 & $\begin{array}{l}\text { Accurately plan and adopt the procurement process in collaboration with our } \\
\text { suppliers. }\end{array}$ & 0.801 & \\
\hline 2.4 & Stabilize procurement with our suppliers. & 0.780 & \\
\hline 2.5 & Share real-time demand forecasts with our suppliers. & 0.712 & \\
\hline 2.6 & Improve strategic partnerships with our suppliers. & 0.772 & \\
\hline 2.7 & Help suppliers improve their processes to better meet our needs. & 0.735 & \\
\hline 2.8 & Improve the account payable processes for suppliers. & 0.572 & \\
\hline 2.9 & $\begin{array}{l}\text { Improve the transport/logistics processes of logistics partners to deliver } \\
\text { orders just in time. }\end{array}$ & 0.734 & \\
\hline 2.10 & Improve our receiving processes for delivered goods. & 0.770 & \\
\hline \multicolumn{4}{|c|}{ Eigenvalue $=6.007 ; \mathrm{KMO}=0.939 ;$ Bartlett's test of sphericity: $\mathrm{x}^{2}=1342.42, \mathrm{p}<0.001$} \\
\hline \multicolumn{4}{|c|}{ Construct 3: Internal integration } \\
\hline \multicolumn{4}{|c|}{ We have been able to improve our internal logistics processes to: } \\
\hline 3.1 & Improve the integration of data among internal functions. & 0.720 & $65 \%$ \\
\hline 3.2 & Improve real-time communication and linkage among all internal functions. & 0.802 & \\
\hline 3.3 & $\begin{array}{l}\text { Accurately plan and adopt internal processes in collaboration with cross } \\
\text { functional teams. }\end{array}$ & 0.816 & \\
\hline 3.4 & $\begin{array}{l}\text { Make and adopt demand forecasts in collaboration with cross functional } \\
\text { teams. }\end{array}$ & 0.818 & \\
\hline
\end{tabular}




\begin{tabular}{|c|c|c|c|}
\hline 3.5 & $\begin{array}{l}\text { Improve inventory management in collaboration with cross functional } \\
\text { teams. }\end{array}$ & 0.824 & \\
\hline 3.6 & Improve real-time searching of the inventory levels. & 0.818 & \\
\hline 3.7 & Improve real-time searching of logistics-related operating data. & 0.713 & \\
\hline 3.8 & Employ cross functional teams in process improvement. & 0.704 & \\
\hline 3.9 & Improve replenishment of shop floor shelves. & 0.782 & \\
\hline 3.10 & Reduce stock outs in the shop floor shelves. & 0.791 & \\
\hline \multicolumn{4}{|c|}{ Eigenvalue $=6.471 ; \mathrm{KMO}=0.955 ;$ Bartlett's test of sphericity: $\mathrm{x}^{2}=1542.049, \mathrm{p}<0.001$} \\
\hline \multicolumn{4}{|c|}{ Construct 4: Customer integration } \\
\hline \multicolumn{4}{|c|}{ We have been able to improve the business processes with our customers to: } \\
\hline 4.1 & Improve the strength of linkages with our customers. & 0.788 & $61 \%$ \\
\hline 4.2 & Improve regular contacts with our customers. & 0.828 & \\
\hline 4.3 & Improve communication with our customers on products and promotions. & 0.708 & \\
\hline 4.4 & $\begin{array}{l}\text { Make and adopt demand forecasts with a real-time understanding of market } \\
\text { trends. }\end{array}$ & 0.791 & \\
\hline 4.5 & $\begin{array}{l}\text { Improve the customer shopping experience/time/ordering/customising } \\
\text { processes. }\end{array}$ & 0.761 & \\
\hline 4.6 & $\begin{array}{l}\text { Accurately plan and adopt the checkout/dispatch/delivery processes through } \\
\text { a better understanding of market trends. }\end{array}$ & 0.729 & \\
\hline 4.7 & Improve the check-out/dispatch/delivery process of goods. & 0.707 & \\
\hline 4.8 & Improve and simplify the payment receivable process from our customers. & 0.741 & \\
\hline 4.9 & Improve customer feedback process. & 0.682 & \\
\hline \multicolumn{4}{|c|}{ Eigenvalue $=5.491 ; \mathrm{KMO}=0.930 ;$ Bartlett's test of sphericity: $\mathrm{x}^{2}=1192.148, \mathrm{p}<0.001$} \\
\hline \multicolumn{4}{|c|}{ Construct 5: Supply chain performance } \\
\hline \multicolumn{4}{|c|}{ We have been able to develop our supply chain processes to: } \\
\hline 5.1 & Improve product quality. & $\begin{array}{r}\text { Dropped } \\
\text { in EFA }\end{array}$ & $55 \%$ \\
\hline 5.2 & Improve supply chain delivery reliability. & 0.641 & \\
\hline 5.3 & Improve fill rates. & 0.656 & \\
\hline 5.4 & Improve perfect order fulfilment (deliveries with no errors). & 0.759 & \\
\hline 5.5 & Improve supply chain flexibility (react to product changes, volume, mix). & 0.652 & \\
\hline 5.6 & Reduce the cash-to-cash cycle time. & 0.653 & \\
\hline 5.7 & Reduce the total supply chain management cost. & 0.753 & \\
\hline 5.8 & Reduce the cost of goods sold. & 0.742 & \\
\hline 5.9 & Improve value-added productivity (sales per employee). & 0.681 & \\
\hline \multicolumn{4}{|c|}{ Eigenvalue $=4.361 ; \mathrm{KMO}=0.924 ;$ Bartlett's test of sphericity: $\mathrm{x}^{2}=719.727, \mathrm{p}<0.001$} \\
\hline \multicolumn{4}{|c|}{ Construct 6: Organisational performance } \\
\hline \multicolumn{4}{|c|}{ We been able to develop our organisational operations to: } \\
\hline 6.1 & Improve the product delivery cycle time. & 0.715 & $55 \%$ \\
\hline 6.2 & Improve productivity (e.g. assets, operating costs, labour costs). & 0.714 & \\
\hline 6.3 & Improve sales of existing products. & 0.828 & \\
\hline 6.4 & Find new revenue streams. & 0.606 & \\
\hline 6.5 & Build strong and continuous bonds with customers. & 0.741 & \\
\hline 6.6 & Gain precise knowledge of customer buying patterns. & 0.741 & \\
\hline 6.7 & Improve customer satisfaction. & 0.735 & \\
\hline 6.8 & Improve employee satisfaction. & 0.688 & \\
\hline 6.9 & Improve employee health and safety. & 0.701 & \\
\hline
\end{tabular}




\begin{tabular}{|c|r|r|}
$6.10 \quad$ Reduce energy use. & 0.730 \\
\hline Eigenvalue $=6.024 ; \mathrm{KMO}=0.945 ;$ Bartlett's test of sphericity: $\mathrm{x}^{2}=1248.043, \mathrm{p}<0.001$ \\
\hline
\end{tabular}

$\mathrm{KMO}=$ Kaiser-Meyer-Olkin Measure of Sampling Adequacy

Copyright: (c) 2018 de Vass, Shee \& Miah. This is an open-access article distributed under the terms of the Creative Commons Attribution-NonCommercial 3.0 Australia License, which permits non-commercial use, distribution, and reproduction in any medium, provided the original author and AJIS are credited.

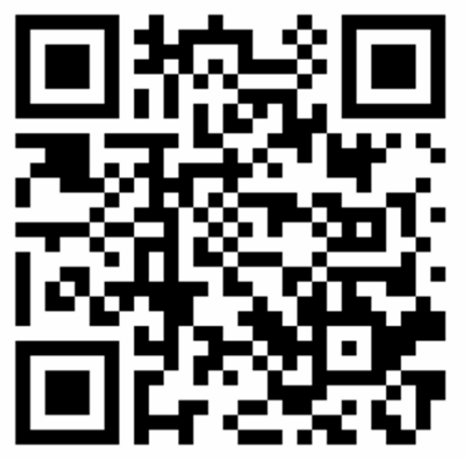

